\title{
Manufacturing Competitive Priorities and Weaknesses of Slovenian Companies: an Empirical Investigation*
}

\author{
Borut Rusjan ${ }^{* *}$
}

This Article examines several research questions relative to the content of manufacturing strategy on the basis of empirical data gathered on a sample of Slovenian manufacturing firms: What were the most important manufacturing competitive priorities of sampled Slovenian companies in the past and what changes in manufacturing competitive priorities are predicted for the future? What systems, policies, practices in production are prevalent in sampled Slovenian firms? What are the most important manufacturing weaknesses that determine the most important strategic decision areas in production in the future? Descriptive statistic has been used to describe the current industry practice and explore characteristics of manufacturing strategy of Slovenian firms.

In diesem Artikel werden auf der Basis empirischer Daten einige Fragestellungen in Bezug auf die Fertigungsstrategien in slowenischen Unternehmen untersucht: Welches waren die höchsten Wettbewerbsprioritäten in der Vergangenheit und welche Veränderungen werden in der Zukunft erwartet? Welche Systeme und Richtlinien sind in den untersuchten slowenischen Unternehmen vertreten? Welches sind die größten Schwächen im Herstellungsprozeß und worin bestehen die damit verbundenen strategischen Entscheidungen für die Zukunft? Unter Einsatz deskriptiver Statistik wird die aktuelle Lage beschrieben, und wichtige Charakteristika der Produktionsstrategie slowenischer Unternehmen werden dargestellt.

\footnotetext{
* Manuscript received: 17.3.99, revised: 27.10.99, accepted: 5.11.99.

** Borut Rusjan, born 1965, Lecturer in Operations Management at the Faculty of Economics, University of Ljubljana. Major areas of research interest: business and operations strategies, quality, application of popular techniques, programs, concepts such as JIT, TQM, Flexible Automation.
} 


\section{Introduction}

A lot of attention has been paid to manufacturing strategy in recent years as an important element in firm's attempts to gain a competitive advantage in the marketplace. Skinner was the first to argue that manufacturing has the potential to strengthen or weaken the company's competitive ability (Skinner 1969). Proper strategic positioning or aligning of operations capabilities can significantly impact the competitive strength and business performance of an organization. Manufacturing can and should represent a competitive weapon. The task is to configure a production system that, through a series of interrelated and internally consistent choices, reflects the priorities and trade-offs implicit in its competitive situation and strategy. Production system is the composite of decisions in a number of key decision areas. There is no best way to manufacture, because different production systems have different operating characteristics (Hayes/ Pisano1994).

Strategic planning process usually involves three basic hierarchical levels of a firm: corporate, business unit and functional level strategies (Fine/ Hax 1985; Kotha/ Orne 1989). This paper focuses on the business unit and functional level strategies. The business strategy specifies the scope of each business and defines the basis on which a business unit can achieve and maintain a competitive advantage within its industry. Many business strategy typologies have been developed, but Porter's model has had the greatest influence on developments in thinking regarding competitiveness at the business unit level. Porter's framework consists of two primary strategies: cost leadership and differentiation. Lower costs and differentiation represent two fundamental types of a competitive advantage a business unit can possess (Porter 1985). The competitive advantage represents the general strategic goal of a business unit. To achieve that general goal, a business strategy has to be developed which defines strategic goals for different business functions.

A functional level strategy specifies how functional strategies, for example, marketing/sales, manufacturing, research and development or finance support the competitive business strategy and complement each other. The literature suggests that manufacturing as a functional level strategy should support the business level strategy of a firm. Manufacturing must also be compatible with the strategies of other functional areas.

The literature indicates that there are different definitions of manufacturing strategy, but there seems to be an agreement that manufacturing strategy is a collective pattern of coordinated decisions within key manufacturing strategic decision areas which should provide manufacturing's strategic goals (Hayes/ Wheelright 1984; Marucheck et all. 1992; Hill 1994). In the manufacturing strategy literature strategic goals of manufacturing are termed manufacturing competitive priorities. Decisions made in different strategic decision areas in 
production represent the means of achieving manufacturing competitive priorities.

Results for manufacturing competitive priorities determine strengths and weaknesses at the business unit level. Business strengths (weaknesses) are represented by those manufacturing competitive priorities that have a positive (negative) contribution to the competitive advantage of the company. The situation in different strategic decision areas in production determines strengths and weaknesses at the manufacturing function level. The situation in different strategic decision areas in production is defined by policies, resources, systems, tools, methods, etc. used in production. Manufacturing strengths (weaknesses) are represented by those strategic decision areas in manufacturing that have a positive (negative) contribution to the achievement of the desired results for manufacturing competitive priorities.

\section{The definition of the research problem and methodology}

There has been a growing interest in the manufacturing strategy in recent years. Our research methodology aimed at gaining some empirically - based understanding regarding the competitive priorities and manufacturing practices of Slovenian companies. Adam and Swamidass (1989) and others (Flynn et all. 1990; Minor et all. 1994) have noted the critical importance of empirical research to the continuing development of the discipline. The purpose of this article is to identify prevalent practitioner priorities and practices on the basis of sample results interpretation. Practitioner priorities and practices were usually studied under the headings of strategy content in manufacturing strategy literature. In the context of manufacturing strategy, content usually refers to two categories: 1) competitive priorities, and 2) strategic decision areas of manufacturing.

The first content category - competitive priorities - means the ways in which firms choose to compete on markets in order to achieve a competitive advantage. Manufacturing competitive priorities usually include cost, flexibility (product mix and volume), quality (design and conformance), delivery performance (dependability and speed) (Vickery 1991; Garvin 1993; Magnan 1994). There is an apparent relationship between Porter's types of a competitive advantage and manufacturing competitive priorities. There is a direct connection of cost leadership at the business level with cost priority at the functional level. Quality, flexibility and delivery on the other side represent types of differentiation strategies for a firm.

The second content category - strategic decisions - represents the means of achieving desired manufacturing strategic goals. Hayes and Wheelwright identify eight strategic decision categories and place them into two groups: structural and infrastructural. Structural categories include capacity, facilities, 
technology, and vertical integration. Infrastructural categories include workforce, quality, production planning/materials control, and organization (Hayes/ Wheelright 1984).

The paper analyzes importance and comparative results for different manufacturing competitive priorities, which can give an insight to competitive orientation of Slovenian companies. Respondents evaluated the degree of importance that each manufacturing competitive priority had for the business to compete successfully over the past two years, and the degree of importance that each manufacturing competitive priority will have for the business to compete successfully over the next two years. Responses were obtained on a 5-point horizontal, numeric scale ranging from 1 representing "extremely unimportant" to 5, "extremely important". Respondents also assessed the current results for manufacturing competitive priorities on the basis of comparison with competitors. Responses were obtained on a 5 point comparative scale (1- "much worse than the competition", 3- "average or equal to the competition", 5- "much better than the competition").

The paper analyzes different decision categories in manufacturing in order to be able to determine which areas in manufacturing represent the most important weaknesses from the point of view of achieving desired manufacturing strategic goals. Every strategic decision area includes different strategic decisions. Strategic decisions are defined as decisions having an important impact on manufacturing competitive priorities. Respondents reported about the level of their agreement with the statement that a current situation in production as a result of a specific strategic decision is appropriate from the point of view of achieving the desired results for manufacturing competitive priorities. Responses were obtained on a 5-point Likert scale ranging from 1 representing "strongly disagree" to 5, "strongly agree".

We have obtained the data for our analysis as a part of an extensive longitudinal research project conducted by a group of researchers at the Faculty of Economics in Ljubljana: "Behavior of Slovenian Enterprises during the Period of Transition to a Market Economy". The project deals with different questions of restructuring the former self-managed enterprises at corporate, business unit and functional level. The project was conducted in 200 large and medium size Slovenian companies which were socially owned and had to go through the privatization process. Sample was chosen on the basis of number of employees. Among 200 companies included in the project sample, 134 were manufacturing companies.

The survey was carried out in the period extending from the second half of 1997 to the end of October 1998. A pilot study was conducted in five companies. After the pilot study, the questionnaire was shortened, because the respondents complained that the questionnaire was too complex. The questionnaire regarding production business function was filled in by the production managers at the 
business unit level. The respondents completed the questionnaire in a noninteractive mode, but were given the opportunity to clarify questions and terms if necessary. We have collected complete data sets for 49 manufacturing companies, which will be used in our analysis.

Participating manufacturing companies came from a wide range of industries as presented in Table 1.

Table (1): Industry distribution of companies included in the sample

\begin{tabular}{|l|c|}
\hline \multicolumn{1}{|c|}{ Industry } & Percentage of companies \\
\hline Food and beverages & $13 \%$ \\
\hline Chemical & $13 \%$ \\
\hline Textile & $11 \%$ \\
\hline Clothing & $11 \%$ \\
\hline Electrical machinery & $9 \%$ \\
\hline Paper & $7 \%$ \\
\hline Leather and footwear & $6 \%$ \\
\hline Other & $30 \%$ \\
\hline Total & $100 \%$ \\
\hline
\end{tabular}

The data analysis method involved the descriptive statistics, which is used to describe industry practice. The average of assessments for every manufacturing competitive priority, and for every strategic decision in manufacturing included in analysis has been calculated.

\section{Discussion of results}

\subsection{Competitive priorities}

In the study measures of seven manufacturing competitive priorities were collected. The averages of assessments of importance and comparative results for different manufacturing competitive priorities are presented in Table 2.

We are using aggregated data so it is difficult to make concise statements about business strategies in singular companies. However, the results offer some interesting conclusions especially if we compare all three assessments: 
Table (2): The importance of manufacturing competitive priorities (MCP) over the past two and over the next two years, and the results for MCP based on comparison with the competition

\begin{tabular}{|l|c|c|c|}
\hline \multirow{2}{*}{} & \multicolumn{3}{|c|}{ Average weighted assessment of : } \\
\cline { 2 - 4 } & $\begin{array}{l}\text { importance } \\
\text { of MCP over } \\
\text { past two } \\
\text { years }\end{array}$ & $\begin{array}{l}\text { importance } \\
\text { of MCP over } \\
\text { next two } \\
\text { years }\end{array}$ & $\begin{array}{l}\text { comparative } \\
\text { results for } \\
\text { MCP }\end{array}$ \\
\hline 1. Low cost of production & 3.85 & 4.78 & 3.24 \\
\hline $\begin{array}{l}\text { 2. Ability to produce products which } \\
\text { have functionality, technical } \\
\text { capability, esthetical and other } \\
\text { features that are better than or } \\
\text { nonexistent in competitive products }\end{array}$ & 3.80 & 4.67 & 3.76 \\
\hline $\begin{array}{l}\text { 3. Flexibility of production } \\
\text { determined as the capability to } \\
\text { produce broad product mix, to accept } \\
\text { special customer orders, to produce } \\
\text { products with many options in size, } \\
\text { color and other features }\end{array}$ & 3.59 & 4.50 & 3.96 \\
\hline $\begin{array}{l}\text { 4. Flexibility of production } \\
\text { determined as the capability to } \\
\text { smoothly introduce new or } \\
\text { technologically improved products }\end{array}$ & 3.87 & 4.67 & 3.58 \\
\hline $\begin{array}{l}\text { 5. Quality of products determined as } \\
\text { the conformance of products to } \\
\text { specifications }\end{array}$ & 3.95 & 4.73 & 3.77 \\
\hline $\begin{array}{l}\text { 6. Speed of delivery } \\
\text { 7. Dependability of delivery }\end{array}$ & 4.11 & 4.80 & \\
\hline & & & \\
\hline & & & \\
\hline
\end{tabular}

1) The assessment of the importance of manufacturing competitive priorities over the past two years shows that dependability of delivery and quality of products determined as the conformance of products to specifications were rated as the most important by manufacturing managers. Similar studies previously done in Slovenia obtained the same results, with the dependability of delivery and the conformance of products to specifications at the top of the list, despite the fact that the respondents in 
the studies were managing directors or top management (Vršec 1990; Pučko 1994; Pučko/ Lahovnik 1996). Similar responses from chief executives and manufacturing managers suggest that there is an appropriate fit between the two levels in organization from the point of view of achieving a competitive advantage of the business unit. This could also mean that manufacturing managers' role in business strategic planning process is appropriate. Manufacturing is an active participant that helps define business strategy by bringing various constraints, imposed upon the business by manufacturing capabilities to the strategic planning process (Anderson et all. 1991). Production managers were asked about the degree of their involvement into the process of the business strategy development: $40 \%$ responded that they were completely involved, and $29 \%$ responded that they were strongly involved.

Dependability of delivery and conformance of products to specifications are especially important to producers of components. This shows that Slovenian companies were trying to gain a competitive advantage on the basis of developing capabilities that are characteristic for a good, established supplier, rather than on the bases of capabilities that are characteristic for an innovative, flexible producer with superior products. It seems that Slovenian companies tried to improve their market position more by improving systems for producing existing products than by intensive development and introduction of new products.

2) There are no major differences between the perceived importance of manufacturing competitive priorities over past two years and the achieved results in manufacturing competitive priorities compared with competition. The only exception is the low manufacturing cost priority, where the achieved result is notably worse than its importance. This could lead to conclusion that manufacturing managers currently see production costs as an important obstacle in the way of gaining the competitive advantage. Even if the low production cost could not be considered as an order winning criteria as the three other competitive priorities had a higher importance rating, it is probably a very important qualifying criteria (Hill 1994). This high discrepancy between the level of importance and the achieved result will probably lead to many manufacturing improvement programs oriented towards lowering production costs in the future.

3) The assessment of the importance of different manufacturing competitive priorities over the next two years tells us what is the general direction of Slovenian companies to achieve a competitive advantage. It shows whether companies mainly follow a cost leadership or a differentiation strategy. It is interesting that the assessed importance of all manufacturing 
competitive priorities over the next two years increased noticeably compared to the assessment of their importance over the past two years. We can conclude that the prevalent manufacturing managers' opinion is that competition is becoming much stronger and will probably demand important improvements in manufacturing capabilities in order to remain competitive.

On the other hand, high average scores for all manufacturing competitive priorities also mean that bases for competition in the future are not exactly and specifically determined. This leads to conclusion that there is a danger for singular companies to become stuck in the middle from the point of view of their business strategy (Porter 1985). At the manufacturing level this means that companies do not follow concept of focus.

One of the basic underpinnings of manufacturing strategy research is that choices among various competitive priorities embody trade-offs. Skinner argued that different approaches to gain a competitive advantage place different demands on the production system of the company (Skinner 1969). The concept of focus requires consistent and explicit choice of the extent to which aspects such as delivery, cost, flexibility and quality are provided for by the manufacturing system. It is both difficult and potentially dangerous for a company to try to compete by offering superior performance along all manufacturing competitive priorities simultaneously (Wheelwright 1984).

According to the results, there is lack of clear direction of what is most important in order to gain or maintain a competitive advantage of a company in the future. Therefore it is difficult for production managers to choose appropriate improvement programs for the future. There is an important discrepancy between perceived present comparative results for competitive priorities and perceived importance of competitive priorities in the future. If production managers try to improve performance on every yardstick, there are serious doubts about the possible effectiveness of such improvement attempts. It requires a huge creative effort on the part of the practitioner to choose appropriate policies, systems, methods and tools among many available options and construct a coherent production system. Manufacturing strategic goals are sometimes conflicting and this demands prioritization. A framework for balancing competing objectives is needed in order to develop effective production systems.

\subsection{Strategic decision areas}

The current situation in different strategic decision areas can have a positive or a negative contribution to the achieved level of results in manufacturing competitive priorities and competitiveness of the business. The current situation is determined by policies, practices, systems, methods, tools, resources used by the company. They define the characteristics of the production system and 
determine the capability of the production system to achieve its strategic objectives. In the study manufacturing managers were asked about their agreement with the statement that the current situation in a specified strategic decision area is appropriate from the point of view of achieving the desired results for manufacturing competitive priorities.

For the purpose of our study, manufacturing strategic decisions were classified into six strategic decision areas: work force, process-technology, materials, and planning, organization and control of production. Each strategic decision area includes different strategic decisions. All decision areas include 53 strategic decisions. Results show that most problematic strategic decisions in production on average were: available managerial knowledge, variability of processes (determined by the number of defects and time needed for repair), use of information technology, degree of automation of different phases of production process, balance and average utilization of capacity, relationship with suppliers (regarding price, quality, speed of delivery, interchanges of information needed for planning, frequency of deliveries, cooperation in the design of products and development of technology), motivation of workers and information system in production. Median of the assessments of appropriateness of these eight strategic decisions was three. This means less than a half of the production managers stated they agreed or strongly agreed that situation connected with the decisions mentioned was appropriate from the point of view of achieving the desired results for manufacturing competitive priorities. We will discuss and explain the results for the eight strategic decisions by presenting some empirical data obtained in our study.

\subsubsection{Available managerial knowledge}

Different empirical studies highlighted the problem of marked lack of well qualified and ambitious people in production management (Oakland/ Wynne 1991; Skinner 1985) and of a low use of production management techniques in manufacturing (Oakland/ Sohal 1987). On the other side authors emphasized management as the most important factor that differentiated the world-class manufacturers from their competitors (Roth et all. 1992).

A relatively low assessment of available managerial knowledge by manufacturing managers demonstrates the assertion of production managers that the future of manufacturing in Slovenia is tied to the ability of manufacturing to attract better people and retain them. At present manufacturing function in Slovenia does not compete effectively for a high quality personnel. Few of the top young people choose manufacturing over the perceived glamour of marketing and finance for example. Attitudes towards manufacturing careers often prevent the best people from beginning or sustaining careers in manufacturing. 
Efficient recruiting and providing continuing extensive training programs in quality, cost management, productivity improvement, team building, etc. for executives and managers have become an imperative in every company that wants to become or remain a world-class manufacturer. Opinion that available managerial knowledge represents a weakness shows that manufacturing managers see the necessity of improvements related to managerial knowledge in order to cope with increased competitive demands in the future.

\subsubsection{Variability of processes}

Variability of processes has an important impact on the dependability of delivery and on the conformance of products to specifications. Those two manufacturing competitive priorities were rated as the most important priorities in the past, and together with low cost of production they represent the most important manufacturing competitive priorities for the future. Variability of processes also has a big influence on the cost of production because it determines idle time and utilization of the equipment. With increased automation it is becoming even more important for equipment to operate reliably within specification.

Production managers were asked which approach to maintenance was more emphasized, remedial or preventive, and $66 \%$ responded that it was the preventive maintenance. Preventive maintenance includes any actions such as adjustments, replacements and basic cleanliness that forestall equipment failures. Activities performed in preventive maintenance aim to keep equipment operating acceptably and reduce the likelihood of breakdown.

Managers' opinion that variability of processes represents a manufacturing weakness shows that managers are not satisfied with the effectiveness of their maintenance programs. Managers will have to continue to work on introducing, implementing and improving total productive maintenance programs. Total productive maintenance represents a full agenda of procedures that improve the dependability of equipment, with emphasis on maintaining equipment before it breaks down. It puts primary responsibility for preventive maintenance on the equipment operator. Operator-centered maintenance is the core concept in the total productive maintenance approach. It is also the reason why the full implementation of the total productive maintenance is not easy to achieve. It requires an important change of the mentality and a lot of training before maintenance tasks can be transferred to machine operators.

\subsubsection{The degree of automation of different phases of production process}

Automation represents a system, process, or piece of equipment that is selfacting or self-regulating, substituting mechanical or electronic devices for human observation, effort and decision making. There are two basic types of automation. The first is represented by highly efficient large-scale plants build in some mass productive industries. Typical for this "fixed" type of automation is 
the use of a transfer line that represents a fixed-path conveyor with singlepurpose equipment mounted along the sides. Very narrowly specialized mechanical automation is typical for these plants and because of that they could not be adapted economically to market pressures for more frequent and substantial changes in product designs and product mix. On the other side this process specialization permits low unit costs. The second type is programmable, flexible automation that is based on the use of information technology. This type of automation offers more flexibility than transfer lines, but requires higher investment. Programmable automation makes it possible to envisage the production of less standardized products in a quasi - continuous process. The characteristics and effects of this type of automation are discussed below.

Managers were asked if parts of different phases of production process are highly automated (high automation implies that an operation is performed with little human intervention or involvement) and what percentage of different phases is highly automated. Responses are shown in Table 3:

Table (3): Extent of automation of production processes

\begin{tabular}{|l|c|c|}
\hline & $\begin{array}{l}\text { \% of responses that part } \\
\text { of the phase is highly } \\
\text { automated }\end{array}$ & $\begin{array}{l}\text { Average \% of automation } \\
\text { of the phase }\end{array}$ \\
\hline Tool change & $17 \%$ & $24 \%$ \\
\hline Job or product processing & $64 \%$ & $50 \%$ \\
\hline Process monitoring & $54 \%$ & $43 \%$ \\
\hline Material movement & $39 \%$ & $36 \%$ \\
\hline Quality control & $33 \%$ & $38 \%$ \\
\hline
\end{tabular}

Responses in Table 3 show a different occurrence rate of automation in different phases of the production process and also a different extent of automation in different phases. As we would expect job or product processing is most often automated and this part of production process is also automated to the highest degree. A speculative conclusion that the amount of automation is not very low can be made also for the other parts of production process. The term speculative conclusion was used because it is difficult to determine what is an optimal extent of automation, especially for a sample that includes different industries. Sharma got similar results in his study in 1987 (Sharma 1987). According to our knowledge, no recent studies exist that would enable better comparisons.

The question is why do production managers see the current extent of automation as a manufacturing weakness. According to our results 
manufacturing managers see production costs as an important obstacle to improve competitiveness and high discrepancy between the level of importance and achieved result for low manufacturing cost priority will probably lead to many manufacturing improvement programs oriented towards lowering production costs in the future. Particularly in the growth, maturity, and saturation phases of the product life cycle, price becomes an increasingly important manufacturing competitive priority. In these phases of the product life cycle for which increased standardization is characteristic cost reduction was traditionally obtained through programs of mechanization and automation. Especially if we take into account the high cost of labor in Slovenia compared with other Eastern European countries, the automation can be seen as important in reduction of direct labor content. On the other hand increased automation could have a negative effect for the flexibility of production determined as the capability to produce broad product mix, to accept special customer orders, to produce products with many options in size, color and other features. If we bear in mind relatively low importance of that manufacturing competitive priority we can conclude that managers see increased automation of production process as important mean of achieving the reduction of cost.

\subsubsection{Extent of use of information technology}

We can distinguish between two basic uses of information technology in production. Information technology can be used for management of information flows. This includes the collection of information in centralized data banks, the processing of information into required analyses and reports as well as the making results available promptly and widely (Gold 1989). We will discuss application of the information technology for managing the information systems later.

The second use of information technology is computerized design (computer assisted drafting, design, and engineering) and production (computer controlled processes, automatic materials handling, automatic storage and retrieval system). Manufacturing technology developments created a range of programmable automation systems that seem to allow for a much greater flexibility in manufacturing. There are different types of computerized manufacturing technologies: most commonly mentioned are CAD (Computer Aided Design), CAM (Computer Aided Manufacturing), FMS (Flexible Manufacturing Systems) and CIM (Computer Integrated Manufacturing). CAD means designing products using a computer and a data-base of part numbers allowing for speed and simplification through increased standardization. CAM is the technology of linking assembly machines, machine tools, computers, and controls together to convert electronic design generated by CAD, and scheduling data into actual product. Signals to and from the computer enable it to monitor and control the actual production processes. An FMS uses information technology to integrate direct numerical control (DNC) system, robotics, and 
material handling, to form a highly automated and flexible manufacturing system (Attaran 1989). A FMS represents a group of machines with reprogrammable controllers linked by an automated materials-handling system and integrated through a central computer. CIM represents the total integration of product-design, engineering, process planning, and manufacturing through computer system.

Production managers were asked what types of information technology are used in production. Responses are shown in Table 4.

Table (4): Types of information technology used in production

\begin{tabular}{|l|c|}
\hline Type of information technology & $\begin{array}{l}\text { \% of responses that certain type of } \\
\text { information technology is used in } \\
\text { production }\end{array}$ \\
\hline Computer Aided Design & $42 \%$ \\
\hline Computer Aided Manufacturing & $54 \%$ \\
\hline $\begin{array}{l}\text { Computerized Production Planning and } \\
\text { Control }\end{array}$ & $73 \%$ \\
\hline
\end{tabular}

These responses show that the degree of penetration of information technology to production in Slovenian companies is not low. Why do then production managers see current amount of use of information technology as a manufacturing weakness? We see two possible reasons for such an assessment: a) manufacturing managers see more extensive use of information technology as an important mean to simultaneously improve different manufacturing competitive priorities, b) manufacturing managers are dissapointed with the results achieved after the introduction of information technology in the past. We discuss both possible reasons below.

Programmable automation is expected to improve performance of production systems on different lines. It offers the capability of producing high variety with low cost and high quality. This means that it alters the traditional concept of trade-offs in production (Adler 1989). The importance of traditional manufacturing trade-offs, for example flexibility versus cost, flexibility versus quality, delivery versus quality and quality versus cost, is diminishing, as implementation of programmable automation is promising improvements in all competitive priorities. According to our results, manufacturing managers perceive that the competition in the future is becoming much more severe. It is possible that they see a more extensive use of information technology as the basic means to achieve simultaneous improvement of all manufacturing competitive priorities and thus assure competitiveness in the future. This might be the reason why production managers in Slovenia assessed the current extent 
of information technology use as a relatively low contributor to the achievement of the desired results for manufacturing competitive priorities.

This might also show an overrelyance of production managers to the advantages of flexible automation. It is important to note that many of the benefits usually ascribed to the new technologies can frequently be obtained through better managed plants and use of simpler, less expensive methods and technologies. Different techniques that are usually named under the umbrella of just-in-time and total quality management programs can bring a good proportion of improvements that new technologies promise to bring. Programs such as just-intime, total quality management, business process reengineering and programmable, flexible automation have often been promoted as universal solutions to problems that manufacturing managers face because of increased competition. These programs usually have similar goals, for example increasing flexibility, improving quality, shortening delivery times, lowering costs, etc.. Choosing appropriate combination of techniques that will be used for improvements in competitiveness is one of the most important tasks of the production manager today. More extensive use of information technology can be an important approach in increasing competitiveness, but it only works if companies have appropriate layouts, control of material flows, maintenance procedures, quality procedures, training programs, suppliers' relationship, etc. A company that lacks management effectiveness and coordination to operate standard technology well will probably add to its problems by investing in advanced use of information technology. Simplifying and improving production processes before modernizing them can decrease the need for investments in automation. Simplification and improvement of production processes are commonly based on reduction or elimination of non value added activities, for example transporting, stocking, sorting, controlling quality and data gathering with techniques such as cellular manufacturing, emphasis on "doing things right the first time", employee involvement, failsafing or foolproofing, group technology, inspection of incoming materials, simplified material flow, supplier certification, reduction of work in process inventories, variety reduction, standardization, etc.. Reduction and elimination of non value added activities enables clarification of what investments to modernization of technology are really necessary for improvement of the competitiveness of the company.

We have to take into account that programmable, flexible automation has many problems related to its implementation. Computerized system, particularly one with extensive organizational impact, is extremely difficult to implement. Adler found out that implementation of CAD/CAM systems required changes in skills, procedures, structure, strategy and culture (Adler 1988). Successful design and implementation of complex programmable automation require integration and co-ordination of a broad range of different decisions. Such applications are likely to require the hiring of new kinds of technical specialist, broad changes in 
management practices and support systems. Another problem with extensive introduction of programmable automation is a tremendous capital investment required up front.

Authors also reported about many problems with effective evaluation of proposals for additional applications of information technology. The major drawback of traditional discounted-cash-flow methods is that they fail to quantify the so-called "intangible" benefits, which are connected to the strategic role of manufacturing capabilities. There appears to be a consensus that evaluation of far-reaching technological changes connected with programmable automation should be conducted on an explicitly strategic foundation (Gold 1982; Hayes/ Jaikumar 1988; Adler 1988).

\subsubsection{Balance and average utilization of capacity}

Balance and average utilization of capacity are mostly determined by long term fixed capacity adjustments and scheduling. Production managers were asked whether their capacity expansion usually led or lagged behind the demand, and $91 \%$ responded that they followed the development of demand. This represents a conservative approach, which builds a negative cushion into the capacity plan. This approach should ensure the company a high capacity utilization. However many companies in Slovenia have problems with low utilization of capacity because their capacities were built for the demand of the former Yugoslavian market. Even though many companies have gone through the reorientation of markets, there are still companies that have not completely neutralized the partial loss of the Yugoslavian market. Balance and utilization of capacity assessed as a manufacturing weakness might be the reason for the high discrepancy between the level of importance and achieved result of low manufacturing cost. This leads to a conclusion that companies will have to sell off part of the company assets or further continue export expansion that was characteristic for many companies after Slovenia become independent.

In the short term, balance and average utilization of capacity depend on scheduling of production. The master schedule is a statement of what the company expects to manufacture expressed in specific configurations, quantities, and dates. An important tool used with master scheduling to insure better utilization of capacity is rough-cut capacity planning, a computer-based method of determining current and future work-center loads and determining the labor and machine resources needed to achieve planned outputs. Rough-cut capacity planning is used to provide a quick capacity check of a few critical resources to insure the feasibility of the master production schedule. On the basis of rough-cut capacity planning we either adjust master production scheduling by changing due dates or adjust short term capacity in order to achieve balance in available and required capacity. In our study only $37 \%$ of production managers responded that they used a computerized MRP system for 
determining material requirements. These means that only few companies have efficient capacity requirements planning. The consequence of this might be a manufacturing weakness determined by lower average capacity utilization.

\subsubsection{Relationship with suppliers regarding price, quality, speed of delivery, interchange of information needed for planning, frequency of deliveries, cooperation in the design of products and development of technology}

There are two popular, but diametrically opposed views on supplier-relations strategy: the competitive and the cooperative (Fine/ Hax 1985). With the competitive approach dependence on a supplier is to be avoided. It recommends developing multiple sources for materials inputs and tapered integration. Buyersupplier relationships resemble spot contracting more than long-term contracting. The cooperative approach recommends moving away from short term contracts to longer, more stable contacts and reliance on a few, dependable suppliers: awarding business to a limited number of suppliers to foster a cooperative relation. Relationship is based on mutual dependence and trust and suppliers are given advice and training. Each approach is practiced by successful firms. However, recent trend seems to be toward the cooperative approach (Fine/ Hax 1985; Roth et all. 1992)

In our study $87 \%$ of production managers answered that long term relationship with suppliers was prevalent. Managers were also asked what was the most important criteria in supplier selection. Responses are shown in Table 5:

Table (5): Most important criteria in supplier selection

\begin{tabular}{|l|c|}
\hline \multicolumn{1}{|c|}{ Criteria } & \% of firms \\
\hline Quality & $45 \%$ \\
\hline Delivery & $25 \%$ \\
\hline Price & $24 \%$ \\
\hline $\begin{array}{l}\text { Other (ISO, references, development, } \\
\text { servicing, etc.) }\end{array}$ & $6 \%$ \\
\hline Total & $100 \%$ \\
\hline
\end{tabular}

The relatively low importance of price as the primary criteria for choosing the suppliers confirms orientation of companies towards long term relationship. However, on the other side managers' answers about the degree of their agreement with the statement that they have a good cooperation with suppliers from the point of view of training, design of products and development of technology were not so confirmative for the hypothesis of the good long-term 
relationship with suppliers. The average assessment for that question was 2.71 (on a 1- strongly disagree to 5- strongly agree Likert scale). The result show that orientation towards a cooperative relationship is becoming popular and being implemented only recently, and that the concept has not been implemented on a broader scale in Slovenia. Especially higher forms of cooperation with suppliers are still in the developmental phase. This type of cooperation is the most difficult to achieve, because it does not only demand a different relationship of a purchasing department with supplier, but also a coordination of different business functions of a company in their relationship towards the supplier. A low assessment of appropriateness of relationship with suppliers might indicate that manufacturing managers see improvements possible in the relationship with suppliers in order to cope with more severe competition in the future. The emphasis on the long term relationship with suppliers is probably the right decision for most companies, but many of them will have to put more efforts to be able to achieve real benefits from cooperative relationship with their suppliers in the future.

\subsubsection{Motivation of workers}

There are different causes for low motivation of Slovenian workers. Despite the specific self management system in former Yugoslavia in which the participation of workers in the decision-making process should have developed at a very high level, the actual level of participation was low. The result of the difference between formal and actual participation in decision-making was dissatisfaction among workers. Motivation probably decreased further with restructuring processes in Slovenian companies, started after Slovenia had become independent. Those processes increased the power of management and often led to work force reductions.

Motivation of workers has an important impact on results of several manufacturing competitive priorities. Assessment of the motivation of workers as a weakness implies manufacturing managers' opinion that improved motivation of workers represents an important means for cooping with expected more severe competition in the future. Low assessment shows that Slovenian managers will have to put more efforts into improvement of motivation. To achieve this goal they can choose from a broad range of possible activities such as: employee involvement through allowing and encouraging employee decision making and implementation of their ideas; free up their time to create ideas; communicate what is expected of employees; provide employee recognition so that individual employees or teams are formally recognized through awards, gifts, time off, merit pay increases, bonuses and parking privileges; start quality of work-life initiatives aimed at improving the work environment with job enrichment, cleanliness, noise reduction, benefits, meetings, etc. 


\subsubsection{Manufacturing information system}

Manufacturing information systems' objective is collecting data to assist in analyzing, planning and controlling production. Manufacturing information system usually collects two types of data: financial data including variable and fixed costs, and non-financial physical measures of quantities of products produced, yields, process times, order progress, order status, defects, set-up and down time, inventory levels, deliveries met, etc.

We mentioned the use of information technology in production for management of information flows. Administrative (or control) automation includes application of computers in accounting, capacity planning, scheduling, purchasing, inventory control systems, material requirements planning, shopfloor tracking systems, quality reporting, shipping and distribution. Two well known comprehensive information systems that tried to integrate many fundamental functions of planning and control in production and have become extensively used in production are: a) Manufacturing Requirements Planning (MRP) which represents a computerized information system for tracking inventory and scheduling stock replenishment orders and b) Manufacturing Resource Planning (MRP II) which represents a comprehensive planning and control system using the master production schedule as a basis for scheduling capacity, shipments, tool changes, design work and cash flow.

Nowadays the availability of computer software can produce accurate and detailed data on basic operations. Quality of the information system is assessed on the basis of the availability of cost, quality, inventory and materials flow related data: the degree to which managers have access to data to aid in monitoring, decision making and learning. Despite the development of integrated computer-based systems that help control inventory levels, material flows, quality and costs, manufacturing information systems often seem to fail to satisfy the production management needs. It seems that Slovenian production managers share the prevalent opinion of inadequacy of current information systems in production. One of the reasons is the fact that information system has become dominated by the financial reporting system. Many authors noted that traditional management accounting methods have not provided the type of information necessary to operate the factories and make strategic decisions (Morgan 1989; Harmon/ Peterson 1990; Swann/ O'Keefe 1991a,b). The information system within an organization has often been developed with the emphasis on meeting external reporting requirements instead of quarantining proper efficiency evaluation of the production process. Proper evaluation of the production process represents basis for continuous improvement necessary in today turbulent increasingly demanding environment. Another important problem is the preoccupation with the technology component of information systems. Many business executives have delegated responsibility for information 
systems to the computer technologists and as a result they received technologyfocused solutions for business problems that were primarily strategic.

In the production managers' opinion information system is a manufacturing weakness, because it does not contribute appropriately to better decision making. Perceived increased competition in the future demands better decision making. Improved information systems would contribute to better decision making and consequently to possible improvement of different manufacturing competitive priorities.

\section{Conclusion}

The purpose of our research was to gather systematic information about manufacturing strategic priorities and manufacturing practices in Slovenian companies. The study was based on questionnaire responses received from manufacturing managers in 49 Slovenian companies. With analysis of empirical data we evaluated strategic orientation of manufacturing, and determined and explained the most common manufacturing weaknesses. The analysis was based on the differentiation of two levels of strategy development: business and functional. Major findings of our study are:

A) Dependability of delivery and quality of products determined as the conformance of products to specifications were rated as the most important manufacturing competitive priorities by manufacturing managers in the past two years. That shows that Slovenian companies tried to improve their market position mainly by improving systems for producing existing products rather than by intensive development and introduction of new products.

B) The result in low manufacturing cost priority is notably worse than its importance which implies that in the future many manufacturing improvement programs oriented towards lowering production costs will be implemented.

C) Manufacturing managers prevalent opinion is that competition is becoming much stronger. On the other hand results show that there is a lack of clear direction of what is most important in order to gain or maintain a competitive advantage of a company in the future. It seems that production managers do not realize that it is both difficult and potentially dangerous for a company to try to compete by offering superior performance along all manufacturing competitive priorities simultaneously.

D) According to results most problematic areas in production on average are managerial knowledge; variability of processes; use of information technology; the degree of automation of different phases of production 
process; balance and average utilization of capacity, relationship with suppliers; motivation of workers; information system in production.

We discussed possible reasons for low assessment of appropriateness of those decisions. Reasons are various, including objective, environmental, economic and societal factors, inadequate understanding of the relationship between strategic decisions and of the possible effects of different strategic decisions, or simply inadequate decision making in the past. We can conclude that most future activities in the production aiming at improving competitiveness of the companies will try to improve those problematic areas. We presented possible changes and directions for problematic strategic decisions that would improve production system and consequently competitiveness of Slovenian companies.

\section{References}

Adam, E.E./ Swamidass, P.M. (1989): Assessing Operations Management from a Strategic Perspective, in: Journal of Management, No. 2, pp 181-203.

Adler, P. (1988): Managing Flexible Automation, in: California Management Review, Spring, pp 34-56.

Anderson, J. et all. (1991): The Process of Manufacturing Strategy: Some Empirical Observations and Conclusions, in: International Journal of Operations and Production Management, Vol. 11, No. 3, pp 86-110.

Attaran, M. (1989): Strategic Issues in the Automated Factory, in: Industrial Management and Data Systems, No. 4, pp 14-19.

Ettlie, J.E. et all. (ed) (1990): Manufacturing Strategy, Nemetz, P.L., Kluwer Academic Publishers, Boston.

Fine, C.H./ Hax, A.C. (1985): Manufacturing Strategy: A Methodology and an Illustration, in: Interfaces, No. 6, pp 28-46.

Flynn, B.B. et all. (1990): Empirical Research Methods in Operations Management, in: Journal of Operations Management, No. 2, pp 250-284. Garvin, D.A. (1993): Manufacturing Strategic Planning, in: California Management Review, No. 4, pp 85106.

Gold, B. (1982): CAM Sets New Rules for Production, in: Harvard Business Review, Vol. 60, No. 6, pp. 88-94.

Gold, B. (1989): Computerization in Domestic and International Manufacturing, in: California Management Review, Winter, pp 129-143.

Harmon, R.T./ Peterson, L.D. (1990): Reinventing the Factory, The Free Press, New York. Hayes, R./ Jaikumar, R. (1988): Manufacturing's Crisis: New Technologies, Obsolete Organizations, in: Harward Business Review, Vol. 66, No. 5, pp 77-85.

Hayes, R.H./ Wheelright, S.C. (1984): Restoring Our Competitive Edge, John Wiley and Sons, New York.

Hayes, R.H./ Pisano, G.P (1994): Beyond World-Class: The New Manufacturing Strategy, in: Harvard Business Review, Vol. 72, No. 1, pp 77-86. 
Hill, T. (1994): Manufacturing Strategy, Irwin, Burr Ridge.

Kotha, S./ Orne, D. (1989): Generic Manufacturing Strategies: A Conceptual Synthesis, in: Strategic Management Journal, No. 3, pp 211-231.

Magnan, G.M. (1994): An Analysis of the Relationships Between Selected Manufacturing Strategies, Production Competence, and Competitive Priority, Michigan State University, Michigan.

Minor, E.D. et all. (1994): A Review of Empirical Manufacturing Strategy Studies, in: International Journal of Operations and Production Management, No. 1, pp 5-25.

Morgan, M. (1989): Management Accounting in the Modern Production Environment: Is it Good Enough?, in: Industrial Management and Data Systems, No. 3, pp 17-21.

Oakland, S.J./ Wynne, R.M.: Efficiency of UK Engineering Production Management Systems, in: International Journal of Operations and Production Management, Vol. 11, No. 1, pp 14-31.

Oakland, S.J./ Wynne, R.M.: Efficiency of UK Engineering Production Management Systems, in: International Journal of Operations and Production Management, Vol. 11, No. 2, pp 14-26.

Oakland, J./ Sohal, A. (1987): Production and Operations Management Tecniques in Manufacturing: Comparing the United Kingdom and the United States, in: Production and Inventory Management, Vol. 28, No. 3, pp 12-15.

Porter, M.E. (1985): Competitive Advantage, The Free Press, New York.

Pučko, D. (1994): Restructuring Strategies in the Slovenian Firms, Faculty of Economics, University of Ljubljana.

Pučko, D./ Lahovnik, M. (1996): Characteristics of Strategic Restructuring Processes in Slovenian Enterprises, Working Papers, Faculty of Economics, University of Ljubljana.

Sharma, D. (1987): Manufacturing Strategy: An Empirical Analysis, The Ohio State University.

Skinner, W. (1969): Manufacturing-Missing Link in Corporate Strategy, in: Harvard Business Review, Vol. 47, No. 3, pp 136-145.

Skinner, W. (1985): Manufacturing: The Formidable Competitive Weapon, New York : John

Wiley and Sons.

Swann, K./ O'Keefe, W.D. (1991a): Advanced Manufacturing Technology: Investment Decision Process. Part I, in: Management Decision, No. 1, pp 20-31.

Swann, K./ O’Keefe, W.D. (1991b): Advanced Manufacturing Technology: Investment Decision Process. Part II, in: Management Decision, No. 3, pp 27-34.

Vickery, S.K. (1991): A Theory of Production Competence Revisited, in: Decision Science, No. 3, pp 635-643.

Voss, C.A (ed.) (1992): Manufacturing Strategy: Process and Content, Roth, V.A. et all., London : Chapman and Hall.

Voss, C.A, (ed) (1992): Manufacturing Strategy: Process and Content, Marucheck, A. et all., Chapman and Hall, London. 
Vršec, E. (1990): The Evaluation of the Importance of some Characteristics of an Enterprise for its Future Competitive Ability, in: Organizacija in kadri, Vol. 23, No. 1-2, pp 3652.

Wheelwright, S.C. (1984): Manufacturing Strategy: Defining the Missing Link, in: Strategic Management Journal, No.1, pp 77-91. 